\title{
Hidden blood loss and its possible risk factors in minimally invasive transforaminal lumbar interbody fusion
}

\section{Yuanxing Zhou}

First Affiliated Hospital of Dalian Medical University

Jianlong Deng

Xiamen University Affiliated Chenggong Hospital

\section{Xin Fu}

First Affiliated Hospital of Dalian Medical University

\section{Ming Yang}

First Affiliated Hospital of Dalian Medical University

\section{Yu Zhang}

First Affiliated Hospital of Dalian Medical University

\section{Yvang Chang}

First Affiliated Hospital of Dalian Medical University

\section{Gang Xu}

First Affiliated Hospital of Dalian Medical University

\section{Bo Wang}

First Affiliated Hospital of Dalian Medical University

\section{Zhonghai Li ( $\square$ lizhonghaispine@126.com )}

First Affiliated Hospital of Dalian Medical University https://orcid.org/0000-0003-4735-1193

\section{Research article}

Keywords: hidden blood loss (HBL), risk factors, minimally invasive transforaminal lumbar interbody fusion (MIS-TLIF), multiple regression analysis, complication

Posted Date: March 26th, 2020

DOl: https://doi.org/10.21203/rs.3.rs-17801/v1

License: (c) (1) This work is licensed under a Creative Commons Attribution 4.0 International License. Read Full License 


\section{Abstract}

Background Hidden blood loss (HBL) is still not well known or used in the setting of spine surgery. Elucidating absolute and relative amount of $\mathrm{HBL}$ is of great importance in order to avoid potential complications. Therefore, we evaluated HBL and its possible risk factors among patients undergoing minimally invasive transforaminal lumbar interbody fusion (MIS-TLIF) for lumbar degenerative diseases.

Methods Between June 2018 and March 2019, 137 consecutive patients with lumbar degenerative disease, who underwent operation with MIS-TLIF technique were enrolled in this study. The patient's demographic characteristics and blood loss related parameters were collected respectively. Pearson or Spearman correlations analysis were used to investigate an association between patient's characteristics and HBL. Multivariate linear regression analysis was used to confirmed independent risk factors of HBL.

Results A total of 137 patients ( 86 males and 51 females, age range 19-78 years) were reviewed in our hospital. A substantial amount of HBL $(488.4 \pm 294.0 \mathrm{ml}, 52.5 \%$ of TBL) occurred after MIS-TLIF. Multivariate linear regression showed that the age, muscle thickness, The Patients' Society of Anesthesiologists (ASA) classification, patient's blood volume (PBV), total blood loss (TBL), postoperative(i.e., day 2 or 3 ) hematocrit (Hct), Hct loss, and fibrinogen level were independent risk factors for HBL ( $P 1=0.000, P 2=0.002, P 3=0.006, P 4=0.002, P 5=0.003, P 6=0.048, P 7=0.004, P 8=0.070)$.

Conclusion A large amount of HBL was incurred in patients undergoing MIS-TLIF. More importantly, the age, muscle thickness, ASA classification, PBV, TBL, postoperative Hct, Hct loss, and fibrinogen level were independent risk factors for HBL in MIS-TLIF. HBL and its risk factors should be paid more attention to during perioperative period.

\section{Background}

Hidden blood loss (HBL) is not usually recognized by general assessment because of its invisibility, while an association is found between increased blood loss and perioperative complications[1]. HBL can exacerbate postoperative hemoglobin drop, leading to increased transfusion requirement, if not properly managed, it may induce delayed wound healing, increased risk of infection and prolonged postoperative rehabilitation. Since Sehat et al.[2] report that HBL following total hip replacement was $49 \%$ of the total blood loss, surgeons became aware that HBL plays an important role in orthopedic procedures. However, $\mathrm{HBL}$ is still not well known or used in the setting of spine surgery. With respect to spinal surgeries, elucidating absolute and relative amount of $\mathrm{HBL}$ is of great importance in order to avoid aforementioned potential complications.

Minimally invasive transforaminal lumbar interbody fusion (MIS-TLIF) has gained popularity as an alternative for treatment of lumbar degenerative diseases thanks to several superiority, such as minimized surgical trauma, accelerated postoperative rehabilitation, less postoperative complications and reduced intraoperative bleeding[3-6]. In clinical practice, however, there still exist a large number of patients suffering from anemia or related disorders after this minimally invasive surgery. Moreover, the 
degree of postoperative anemia turns out to be not in accordance with the amount of perioperative blood loss. Sehat et al.[2] proposed concept of HBL in 2000, which might be in association with negative postoperative outcomes[7, 8]. According to published studies, the HBL in lumbar fusion surgery ranged from 227 to $600 \mathrm{ml}$, but most surgeons might ignore it[9-11]. A previous study showed that compared with open transforaminal lumbar interbody fusion (O-TLIF), HBL in patients undergoing MIS-TLIF was seriously underestimated, and accounted for a larger percentage of total blood loss (TBL) even though TBL after MIS-TLIF was much less[12]. To the best of our knowledge, there was not research that analyzed the risk factors of HBL in MIS-TLIF. This study could be the first one to investigate this field. Therefore, we retrospectively reviewed medical data of patients who underwent MIS-TLIF in our department in attempt to evaluate $\mathrm{HBL}$ and identify its risk factors.

\section{Methods}

\section{Patient Population}

This was a retrospective clinical study. From June 2018 to March 2019, 137 patients having lumbar degenerative disease at our institution (First Affiliated Hospital of Dalian Medical University) were included in this study. Information gathered included demographic details, etiology, diagnosis, radiological, and laboratory investigations. Pre-, intra- as well as post-operative findings were recorded as well. All patients aged 18 years or older who had lumbar degenerative diseases (lumbar canal stenosis, spondylolisthesis, and lumbar disk herniation) treated by MIS-TLIF were included. Exclusion criteria were patients (1) age less than 18 years; (2) with lumbar infections and tumors; (3) with previous lumbar surgery; (4) unexpectedly suffered dural rupture during surgery; (5)with acute lumbar fracture; (6) combined with blood-related diseases, coagulopathy and severe anemia; (7) with antiplatelet drugs or anticoagulants; (8) with autologous and allogeneic blood transfusion; (9) with intraoperative blood loss greater than $1.5 \mathrm{~L}[13]$.

\section{Data Extraction}

Patient data were collected from electronic medical records system of our institution. Demographic characteristics such as sex, age, weight, height, body mass index (BMI), hypertension (i.e., blood pressure

$\geq 140 / 90 \mathrm{mmHg}$ ), diabetes mellitus (i.e., fasting blood-glucose $\geq 6.1 \mathrm{mmol} / \mathrm{l}$ ), smoking, drinking, surgical duration, muscle thickness, subcutaneous fat thickness, hospital stay, The Patients' Society of Anesthesiologists (ASA) classification, level fused, were assessed and recorded. Blood loss related data such as intraoperative blood loss, preoperative hematocrit (Hct), preoperative hemoglobin $(\mathrm{Hb})$, postoperative (i.e., day 2 or 3) Hct, postoperative (i.e., day 2 or 3) Hb, prothrombin time (PT), activated partial thromboplastin time (APTT), thrombin time (TT), fibrinogen, platelet (PLT), were extracted respectively. The $\mathrm{Hb}$ was aimed to define anemia (i.e., $<120 \mathrm{~g} / \mathrm{L}$ for females and $<130 \mathrm{~g} / \mathrm{L}$ for males)[14]. Preoperative magnetic resonance imaging (MRI) was used to determine distance of the lamina from skin surface, thickness of the paraspinal muscles, and thickness of the subcutaneous fat. These measurements were all performed at the level of L4, using sagittal views (Fig. 1). To prevent interobserver 
variability, measurements were performed three times by the same observer, who was blinded to the operative details.

\section{Calculation of Hidden Blood Loss}

Firstly, patient's blood volume (PBV) should be calculated according to the formula of Nadler et al.[15]: $\mathrm{PBV}=\mathrm{k} 1 \times$ height $(\mathrm{m})^{3}+\mathrm{k} 2 \times$ weight $(\mathrm{kg})+\mathrm{k} 3$, (for male: $\mathrm{k} 1=0.3669, \mathrm{k} 2=0.03219$, and $\mathrm{k} 3=0.6041$; for female: $k 1=0.3561, k 2=0.03308$, and k3 $=0.1833$ ). Secondly, according to the Gross formula[16], total blood loss (TBL) was calculated by multiplying PBV by changes of $\mathrm{Hct}: \mathrm{TBL}=\mathrm{PBV}\left(\mathrm{Hct}_{\text {pre }}-\mathrm{Hct}_{\text {post }}\right) / \mathrm{Hct}_{\text {ave }}$. Where Hct pre $_{\text {is }}$ the preoperative Hct. Hct post $_{\text {is the second or third postoperative Hct. Hct }}$ ave is the average

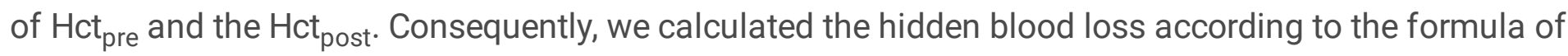
Sehat et al.[17]: $\mathrm{HBL}=\mathrm{TBL}-$ visible blood loss $(\mathrm{VBL})$. Since all the cases did not have postoperative wound drainage, intraoperative blood loss was equal to VBL, which was calculated as the sum of blood in suction containers and soaked gauzes and sponges.

\section{Statistical Analysis}

Data analysis was performed with the SPSS 22.0 software (International Business Machines Corporation, Armonk, State of New York). Student t-test was used to compare differences between pre- and postoperative Hct values and $\mathrm{Hb}$ levels. The chi-squared test was taken to compare pre- and postoperative anemia. Pearson correlation (used for the normal data),spearman correlations analysis (used for the nonnormal data) and multivariate linear regression analysis were established to identify risk factors associated with the HBL, such as gender, age, BMI, hypertension, diabetes mellitus, smoking, drinking, surgical duration, muscle thickness, subcutaneous fat thickness, hospital stay, ASA classification PBV, VBL, TBL, preoperative Hct, preoperative $\mathrm{Hb}$, postoperative $\mathrm{Hct}$, postoperative $\mathrm{Hb}, \mathrm{PT}$, APTT, TT, PLT, and level fused. $P<0.05$ was considered statistically significant.

\section{Results}

A total of 137 patients ( 86 males and 51 females, age range 19-78 years) were retrospectively reviewed in this study. The demographic information are summarized in Table 1. The mean muscle thickness was $38.8 \pm 6.6 \mathrm{~cm}$, while the mean subcutaneous fat thickness was $27.0 \pm 5.1 \mathrm{~cm}$. The mean preoperative Hct and $\mathrm{Hb}$ were $38.8 \pm 4.5$ and $121.1 \pm 16.5 \mathrm{~g} / \mathrm{l}$. The mean postoperative $\mathrm{Hct}$ and $\mathrm{Hb}$ were $32.8 \pm 4.5$ and $105.9 \pm 16.7 \mathrm{~g} / \mathrm{l}$. The mean PBV was $5.0 \pm 0.7 \mathrm{~L}$. The mean HBL was $488.4 \pm 294.0 \mathrm{ml}, 52.5 \% \mathrm{of} \mathrm{TBL}$. The mean VBL was $284.2 \pm 108.4 \mathrm{ml}$. The mean TBL was $772.5 \pm 328.8 \mathrm{ml}$. Hct loss was $5.5 \pm 2.1$ and $\mathrm{Hb}$ loss was $15.2 \pm 7.8 \mathrm{~g} / \mathrm{l}$. There were significant differences between Pre- and post-operative Hct $(P<0.001)$ and $\mathrm{Hb}(\mathrm{P}<0.001)$, and 42 patients developed anemia after surgery $(\mathrm{p}<0.001$, Table 2$)$. 
Table 1

Patients Demographics.

\begin{tabular}{|c|c|}
\hline Parameters & Statistics \\
\hline $\begin{array}{l}\text { Total patients }(n) \\
\text { Sex }(n)\end{array}$ & 137 \\
\hline Male & 86 \\
\hline Female & 51 \\
\hline Age, yr & $49.6 \pm 9.5$ \\
\hline $\mathrm{BMI}, \mathrm{kg} / \mathrm{m}^{2}$ & $26.0 \pm 3.9$ \\
\hline Hypertension (n) & 35 \\
\hline Diabetes mellitus ( $\mathrm{n}$ ) & 31 \\
\hline Smoking (n) & 50 \\
\hline Drinking (n) & 28 \\
\hline Surgical duration, min & $127.7 \pm 52.7$ \\
\hline Muscle thickness, $\mathrm{cm}$ & $38.8 \pm 6.6$ \\
\hline Subcutaneous fat thickness, $\mathrm{cm}$ & $27.0 \pm 5.1$ \\
\hline Hospital stay, d & $11.4 \pm 2.7$ \\
\hline \multicolumn{2}{|l|}{ ASA classification ( $\mathrm{n}$ ) } \\
\hline I & 47 \\
\hline II & 56 \\
\hline III & 27 \\
\hline IV & 7 \\
\hline PBV, L & $5.0 \pm 0.7$ \\
\hline VBL, ml & $284.2 \pm 108.4$ \\
\hline $\mathrm{HBL}, \mathrm{ml}$ & $488.4 \pm 294.0$ \\
\hline TBL, ml & $772.5 \pm 328.8$ \\
\hline HBL/TBL (\%) & $52.5 \pm 18.6$ \\
\hline
\end{tabular}

BMI, body mass index; ASA, American Society of Anesthesiologists; PBV, patient's blood volume; VBL, visible blood loss; HBL, hidden blood loss; TBL, total blood loss; Hct, hematocrit; Hb, hemoglobin; PT, prothrombin time; APTT, activated partial thromboplastin time; TT, thrombin time; PLT, platelet;yr, year; d, day. 


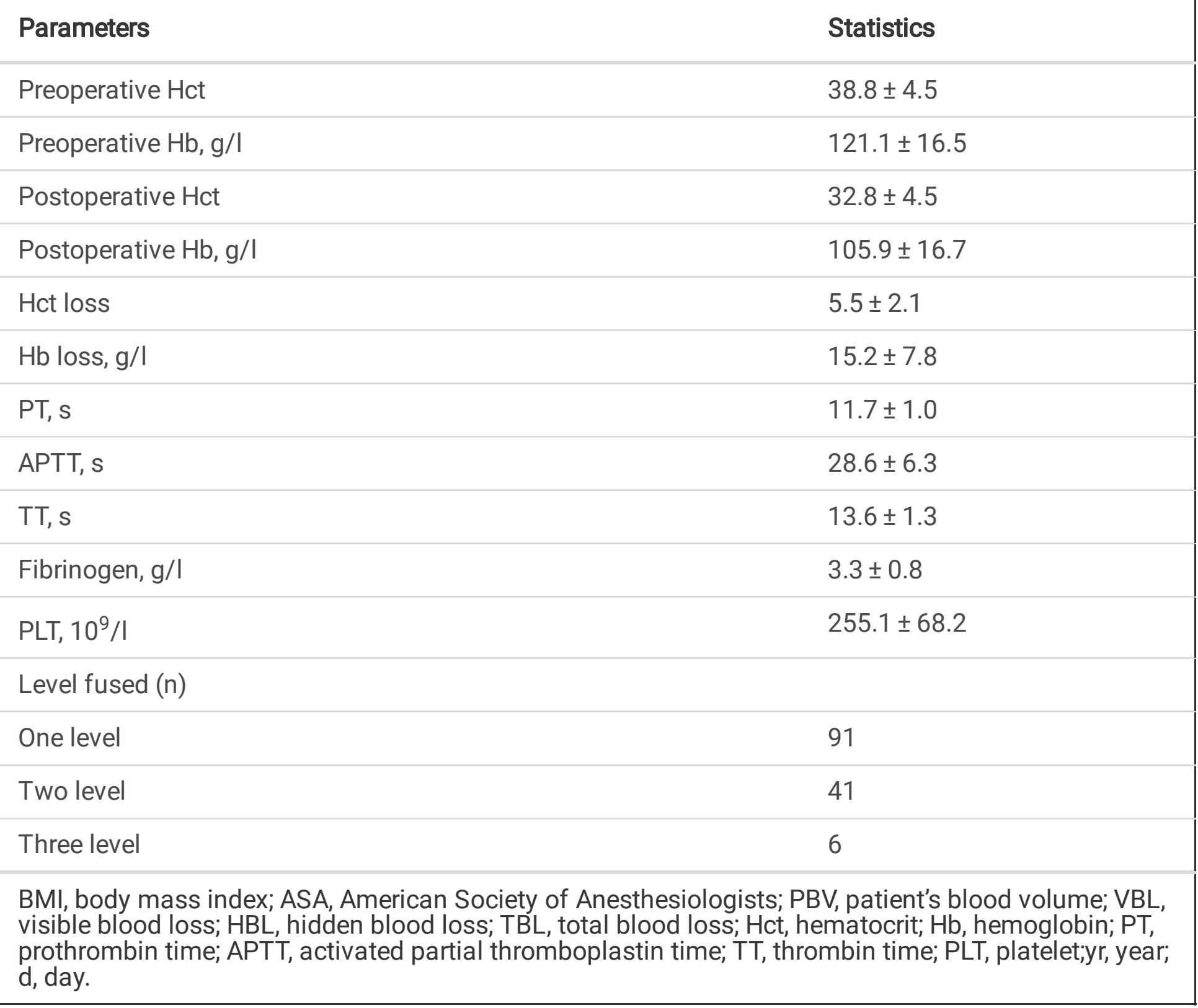

Table 2

Changes in $\mathrm{Hct}, \mathrm{Hb}$ and anemia level following minimally invasive transforaminal lumbar interbody fusion (MIS-TLIF).

\begin{tabular}{|llll|}
\hline & Preoperative & Postoperative & Statistical \\
\hline & $(\mathrm{n}=137)$ & $(\mathrm{n}=137)$ & Significance \\
\hline $\mathrm{Hct}, \%$ & $38.2 \pm 4.5$ & $32.8 \pm 4.5$ & $\mathrm{P}<0.001$ \\
\hline $\mathrm{Hb}, \mathrm{g} / \mathrm{I}$ & $121.1 \pm 16.5$ & $105.9 \pm 16.7$ & $\mathrm{P}<0.001$ \\
\hline Anemia & 76 & 118 & $\mathrm{P}<0.001$ \\
\hline Hct, hematocrit; $\mathrm{Hb}$, hemoglobin. \\
\hline
\end{tabular}


Pearson or Spearman correlation analysis for $\mathrm{HBL}$ found that the following parameters with a $\mathrm{P}<0.05$ (Table 3): age $(P=0.000)$, surgical duration $(P=0.000)$, muscle thickness $(P=0.000)$, subcutaneous fat thickness $(P=0.000)$, ASA classification $(P=0.000)$, PBV $(P=0.000), T B L(P=0.000)$, postoperative Hct $(P=0.000)$, postoperative $\mathrm{Hb}(P=0.000)$, Hct loss $(P=0.000)$, Hb loss $(P=0.000)$, APTT $(P=0.000)$, fibrinogen level $(P=0.000)$, level fused $(P=0.000)$. Multivariate linear regression showed that the age, muscle thickness, ASA classification, $\mathrm{PBV}, \mathrm{TBL}$, postoperative Hct, Hct loss, and fibrinogen level were independent risk factors for $\mathrm{HBL}(\mathrm{P} 1=0.000, \mathrm{P} 2=0.002, \mathrm{P} 3=0.006, \mathrm{P} 4=0.002, \mathrm{P} 5=0.003, \mathrm{P} 6=0.048$, P7 $=0.004$, P8 $=0.070$, Table 4). 
Table 3

Results of Pearson or Spearman correlation analysis for hidden blood loss.

\begin{tabular}{|c|c|c|}
\hline Parameters & Sig (2-tailed) & $\mathbf{P}$ \\
\hline Gender & 0.052 & 0.550 \\
\hline Age & 0.689 & 0.000 \\
\hline BMI & -0.104 & 0.229 \\
\hline Hypertension & 0.054 & 0.533 \\
\hline Diabetes mellitus & 0.088 & 0.308 \\
\hline Smoking & -0.128 & 0.136 \\
\hline Drinking & 0.109 & 0.203 \\
\hline Surgical duration & 0.611 & 0.000 \\
\hline Muscle thickness & 0.794 & 0.000 \\
\hline Subcutaneous fat thickness & 0.466 & 0.000 \\
\hline Length of stay & -0.071 & 0.409 \\
\hline ASA classification & 0.790 & 0.000 \\
\hline PBV & 0.333 & 0.000 \\
\hline VBL & 0.152 & 0.077 \\
\hline TBL & 0.945 & 0.000 \\
\hline Preoperative Hct & -0.009 & 0.917 \\
\hline Preoperative $\mathrm{Hb}$ & -0.062 & 0.470 \\
\hline Postoperative Hct & -0.398 & 0.000 \\
\hline Postoperative $\mathrm{Hb}$ & -0.327 & 0.000 \\
\hline Hct loss & 0.832 & 0.000 \\
\hline $\mathrm{Hb}$ loss & 0.570 & 0.000 \\
\hline PT & -0.130 & 0.131 \\
\hline APTT & -0.331 & 0.000 \\
\hline TT & 0.025 & 0.770 \\
\hline
\end{tabular}




\section{Parameters}

Fibrinogen

PLT

Level fused
Sig (2-tailed)

$-0.873$

0.049

0.567

Values in bold indicate statistical significant. BMI, body mass index; ASA, American Society of Anesthesiologists; PBV, patient's blood volume; VBL, visible blood loss; TBL, total blood loss; Hct, hematocrit; $\mathrm{Hb}$, hemoglobin; $\mathrm{PT}$, prothrombin time; $\mathrm{APTT}$, activated partial thromboplastin time; $\mathrm{TT}$, thrombin time; PLT, platelet.

Table 4

Results of multivariate linear regression for hidden blood loss.

\begin{tabular}{|llllll|}
\hline \multicolumn{5}{|l}{ Unstandardized } & \multicolumn{3}{l}{ Standardized } & \\
\hline Coefficients* & $\beta$ & SE & $\beta$ & $t$ & $\mathrm{P}$ \\
\hline Constant & -145.312 & 135.160 & & -1.075 & 0.284 \\
\hline Age & 3.279 & 0.907 & 0.106 & 3.616 & 0.000 \\
\hline Surgical duration & -0.154 & 0.209 & -0.028 & -0.739 & 0.461 \\
\hline Muscle thickness & 5.683 & 1.754 & 0.127 & 3.241 & 0.002 \\
\hline Subcutaneous fat thickness & -1.487 & 1.564 & -0.026 & -0.951 & 0.344 \\
\hline ASA classification & 32.196 & 11.528 & 0.101 & 2.793 & 0.006 \\
\hline PBV & 58.611 & 18.259 & 0.139 & 3.210 & 0.002 \\
\hline TBL & 0.279 & 0.091 & 0.313 & 3.071 & 0.003 \\
\hline Postoperative Hct & -5.062 & 2.531 & -0.077 & -2.001 & 0.048 \\
\hline Postoperative Hb & 0.150 & 0.404 & 0.008 & 0.370 & 0.712 \\
\hline Hct loss & 39.861 & 13.592 & 0.283 & 2.933 & 0.004 \\
\hline Hb loss & 0.860 & 1.060 & 0.023 & 0.811 & 0.419 \\
\hline APTT & -1.867 & 1.579 & -0.040 & -1.183 & 0.239 \\
\hline Fibrinogen & -72.723 & 15.446 & -0.199 & -4.708 & 0.000 \\
\hline Level fused & -33.994 & 18.593 & -0.066 & -1.828 & 0.070 \\
\hline Values in bold indicate statistical significant. *Dependent variable: HBL (ml). ASA, American Society \\
of Anesthesiologists; PBV, patient's blood volume; HBL, hidden blood loss; TBL, total blood loss; Hct, \\
hematocrit; Hb, hemoglobin; APTT, activated partial thromboplastin time; & & \\
\hline
\end{tabular}




\section{Discussion}

Spinal fusion surgery associated with excessive blood loss has been documented[18-20]. So, the concept of HBL was proposed in 2000[2]. HBL is now paid attention to and considered as an important proportion of total blood loss, but instead, it remains underestimated by most orthopaedic surgeons[17]. Jiang et al.[21] believed that the mean HBL was $337 \mathrm{ml}$, which was $46.8 \%$ of TBL after cervical open-door laminoplasty (EOLP). Ju et al.[10] held that HBL for patients who received anterior lumbar interbody fusion (ALIF) was about $450 \mathrm{ml}$ and averaged $39.2 \%$ of TBL. Our result showed that a substantial amount of hidden blood loss ( $488.4 \pm 294.0 \mathrm{ml}, 52.5 \%$ of TBL) frequently occurred after MIS-TLIF, which was quite larger than expected. Nevertheless, the influential factors correlated to the HBL were not confirmed. In our study, we investigated and identified the risk factors of HBL following this surgery by multivariate linear regression analysis. The results proposed that the age, muscle thickness, ASA classification, $\mathrm{PBV}, \mathrm{TBL}$, and Hct loss were positive independent risk factors of $\mathrm{HBL}$, while postoperative Hct and fibrinogen level were negatively related to HBL.

ASA classification is reportedly an independent risk factor of HBL in anterior cervical fusion (ACF) surgery[22]. The author held that the HBL of patients with ASA classification III was higher than ASA I and ASA II. What is more, some scholars proposed that higher ASA classification was an independent risk factor for blood transfusion in spine fusion surgery[23, 24]. In our series, we obscured a similar outcome. That is, patients with higher ASA classification seem to take more risk attributing to HBL in MIS-TLIF. As ASA classification is defined, the patients with ASA II to IV usually combine with mild or severe systemic diseases. In other words, these patients' function of hemodynamics is out of order and they are apt to have less tolerance towards anemia.

PBV was an independent risk factor of HBL in multiple linear regression analysis In our study, which might relate to patient's weight and height, because PBV was calculated according to the formula of Nadler et al.[15]. Although BMI is also calculated by weight and height, BMI was not clarified as a risk factor in our study. In addition, our result showed that TBL was another independent risk factor, which may have to do with PBV, because TBL was calculated by multiplying PBV by changes of Hct according to the Gross formula.[16]. Based on collected data in our study, the patients with larger TBL were in accordance with higher HBL. Furthermore, postoperative Hct and Hct loss were suggested as independent factors in our series, but not postoperative $\mathrm{Hb}$ and $\mathrm{Hb}$ loss. Nonetheless, $\mathrm{Hct}$ and $\mathrm{Hb}$ were both significant differences between Pre- and post-operative by Student t-test. Some studies suggested that postoperative fluid dilution should be a vital reason to attribute to more Hct change[25, 26], which might be a possible explanation for different significances between $\mathrm{Hct}$ and $\mathrm{Hb}$ related indexes in multiple linear regression analysis.

Our study found that fibrinogen level was negatively related to HBL. Fibrinogen refers to as blood coagulation factor $\mathrm{I}$, which is the major protein in the process of clotting cascade. Wen et al.[18] indicated that a disproportionate increase in $\mathrm{HBL}$ seem to appear for fibrinogen level $\geq 3$ versus $3<$ fibrinogen level $\geq 2$ or $2<$ fibrinogen level $\geq 1$. That is, fibrinogen level was a positive influential factor. After careful 
consideration and analysis, we enable to explain why two studies have contrary outcomes. It is true that patients with higher fibrinogen level are in accordance with hypercoagulation. In their study, patients had postoperative wound drainage after posterior lumbar fusion (PLF). So, when they calculated HBL, they should minus postoperative drainage. However, bleeding likely coagulated in the lacunae or dead space among the patients with higher fibrinogen level, decreasing the volume of postoperative drainage. Then, HBL would be calculated larger. In the contrary, the patients in our study were not provided with wound drainage. Thus, all of postoperative hemorrhage could be seen as HBL. Patients with higher fibrinogen level are liable to form clot and stop bleeding by themselves. Consequently, in our study, fibrinogen level is a positive influential factor of HBL.

In our study, age has a significant correlation with HBL. A previous study proposed that age was the risk factor of HBL in posterior lumbar fusion (PLF), especially for the age of 60 years or above[18]. One possible explanation is that older patients have poor compensatory capacity of cardiovascular system and reduced self-regulatory ability due to angiosclerosis. Another reason might be that bleeding is liable to infiltrating and agglutinating more easily into interstitial spaces, owing to muscle wastage and hypercoagulability in senile patients[27].

Our study firstly considered that muscle thickness was the key factor in predicting HBL in MIS-TLIF, which has not been reported before. We found that muscle thickness was regarded as an index parameter to indicate HBL in lumbar fusion surgery. Surgical techniques may lead to postoperative bleeding on not only bony surfaces and the spinal canal, but soft tissue dissection including muscle and subcutaneous fat. Subcutaneous fat thickness was not turned out to be a risk factor of HBL in our study, whereas muscle thickness was. The explanation for this is that thicker muscle probably suffers more soft tissue injury which would increase perioperative bleeding. Meanwhile, thicker muscle may be associated with larger penetrable tissue compartments, allowing blood to ooze into tissue cavity[28].

It has reported that a large amount of $\mathrm{HBL}$ after spine fusion surgery can bring about adverse consequences, such as lengthened hospitalization time, prolonged postoperative rehabilitation and affected patients satisfaction[29]. The mechanisms of HBL have not been entirely clear. HBL is generally ascribe to two pathways: infiltration of bleeding into the tissue compartment or dead cavities and hemolysis. Erskine et al.[17] suggested that $60 \%$ of HBL was caused by infiltration of bleeding and $40 \%$ by hemolytic reactions. While Sehat et al.[30] believed that the proportion of HBL from extravasation of bleeding and hemolysis was 2:1. In any case, patient's Hct and $\mathrm{Hb}$ should be checked closely before and after surgery to ensure if the patient has anemia or tendency to anemia. Besides, surgeons also need to give priority to patient's age, muscle thickness, ASA classification, PBV, TBL, and fibrinogen level to evaluate that the patient is not at an increased risk of bleeding after surgery.

\section{Study Limitations}

Some limitations should be considered in our study. Since this is a descriptive study, it has potential limitations. The number of patients included in this study was relatively small. In addition, whether fluid 
shift and hemodynamics become stable after 2 to 3 days after spine fusion surgery has not been ascertained. Again, more studies are required to find the accurate time of stability of fluid shift. Finally, we were unable to investigate the influence of racial differences for $\mathrm{HBL}$, because most patients included in our hospital were native residents. Due to these limitations, high-quality observational studies and basic experimental studies are still needed to investigate new risk factors for $\mathrm{HBL}$ among patients undergoing MIS-TLIF further in the future.

\section{Conclusions}

Consequently, it concluded that a large amount of HBL was incurred in patients undergoing MIS-TLIF. More importantly, the age, muscle thickness, ASA classification, PBV, TBL, postoperative Hct, Hct loss, and fibrinogen level were independent risk factors for HBL in MIS-TLIF. HBL and its risk factors should be paid more attention to during perioperative period. Adequate management of the risk factors will help to reduce surgical patients' morbidity, mortality, and length of stay, and save cost for the healthcare institutions.

\section{Abbreviations}

MIS-TLIF: minimally invasive transforaminal lumbar interbody fusion; O-TLIF: open transforaminal lumbar interbody fusion; BMI: body mass index; ASA: American Society of Anesthesiologists; PBV: patient's blood volume; VBL: visible blood loss; HBL: hidden blood loss; TBL: total blood loss; Hct: hematocrit; Hb: hemoglobin; PT: prothrombin time; APTT: activated partial thromboplastin time; TT: thrombin time; PLT: platelet; EOLP: expensive open-door laminoplasty; ALIF: anterior lumbar interbody fusion; PLF: posterior lumbar fusion; ACF: anterior cervical fusion.

\section{Declarations}

\section{Acknowledgments}

We would like to thank the Spinal Degeneration and Neuroprotection Group, Committee of Neuroregeneration and Repair, Chinese Research Hospital Association for making this research possible.

\section{Authors' contribution}

Conception and design: Yuanxing Zhou, Bo Wang, Zhonghai Li. Acquisition of data: Xin Fu, Ming Yang,Yu Zhang, Yvang Chang. Analysis and interpretation of data: Yuanxing Zhou, Jianlong Deng, Gang Xu. Drafting the article: Yuanxing Zhou. Critically revising the article: Zhonghai Li. Reviewed submitted version of manuscript: Zhonghai Li. Approved the final version of the manuscript on behalf of all authors: Zhonghai Li. Statistical analysis: Yuanxing Zhou. Study supervision: Yuanxing Zhou, Bo Wang, Zhonghai Li. 


\section{Funding}

This study was funded by LiaoNing Revitalization Talents Program (XLYC1807131), the Natural Science Foundation of Liaoning Province (20170540294, 2019-BS-079) and the Teaching Reform Research Project of Dalian Medical University $\mathbb{D}$ DYLX19010区. The funders had no role in the study design, data collection and analysis, decision to publish, or preparation of the manuscript.

\section{Availability of data and materials}

Data in contingency tables and the dataset are available from the corresponding author at lizhonghaispine@126.com.

\section{Ethics approval and consent to participate}

Not applicable, as all data was received completely anonymous.

\section{Consent for publication}

Not applicable.

\section{Competing interests}

The authors declare that they have no competing interests.

\section{Author details}

${ }^{1}$ Department of Orthopaedics, First Affiliated Hospital of Dalian Medical University, Dalian, the People's Republic of China. ${ }^{2}$ Key Laboratory of Molecular Mechanism for Repair and Remodeling of Orthopaedic Diseases, Liaoning Province, the People's Republic of China. ${ }^{3}$ Department of Neurosurgery, Xiamen University Affiliated Success Hospital, Xiamen, the People's Republic of China. ${ }^{4}$ Department of Neurosurgery, First Affiliated Hospital of Dalian Medical University, Dalian, the People's Republic of China.

\section{References}


1. Foss NB, Kehlet H: Hidden blood loss after surgery for hip fracture. The Journal of bone and joint surgery British volume 2006, 88(8):1053-1059.

2. Sehat KR, Evans R, Newman JH: How much blood is really lost in total knee arthroplasty?. Correct blood loss management should take hidden loss into account. The Knee 2000, 7(3):151-155.

3. Gu G, Zhang H, Fan G, He S, Cai X, Shen X, Guan X, Zhou X: Comparison of minimally invasive versus open transforaminal lumbar interbody fusion in two-level degenerative lumbar disease. International orthopaedics 2014, 38(4):817-824.

4. Karikari IO, Isaacs RE: Minimally invasive transforaminal lumbar interbody fusion: a review of techniques and outcomes. Spine 2010, 35(26 Suppl):S294-301.

5. Sulaiman WA, Singh M: Minimally invasive versus open transforaminal lumbar interbody fusion for degenerative spondylolisthesis grades 1-2: patient-reported clinical outcomes and cost-utility analysis. The Ochsner journal 2014, 14(1):32-37.

6. Vazan M, Gempt J, Meyer B, Buchmann N, Ryang YM: Minimally invasive transforaminal lumbar interbody fusion versus open transforaminal lumbar interbody fusion: a technical description and review of the literature. Acta neurochirurgica 2017, 159(6):1137-1146.

7. Smith GH, Tsang J, Molyneux SG, White TO: The hidden blood loss after hip fracture. Injury 2011, 42(2):133-135.

8. Miao K, Ni S, Zhou X, Xu N, Sun R, Zhuang C, Wang Y: Hidden blood loss and its influential factors after total hip arthroplasty. Journal of orthopaedic surgery and research 2015, 10:36.

9. Xu D, Ren Z, Chen X, Zhuang Q, Hui S, Sheng L, Li S: The further exploration of hidden blood loss in posterior lumbar fusion surgery. Orthopaedics \& traumatology, surgery \& research : OTSR 2017, 103(4):527-530.

10. Ju H, Hart RA: Hidden blood loss in anterior lumbar interbody fusion (ALIF) surgery. Orthopaedics \& traumatology, surgery \& research : OTSR 2016, 102(1):67-70.

11. Smorgick Y, Baker KC, Bachison CC, Herkowitz HN, Montgomery DM, Fischgrund JS: Hidden blood loss during posterior spine fusion surgery. The spine journal : official journal of the North American Spine Society 2013, 13(8):877-881.

12. Zhang H, Chen ZX, Sun ZM, Jiang C, Ni WF, Lin Y, Wu YS: Comparison of the Total and Hidden Blood Loss in Patients Undergoing Open and Minimally Invasive Transforaminal Lumbar Interbody Fusion. World neurosurgery 2017, 107:739-743.

13. Seng C, Siddiqui MA, Wong KP, Zhang K, Yeo W, Tan SB, Yue WM: Five-year outcomes of minimally invasive versus open transforaminal lumbar interbody fusion: a matched-pair comparison study. Spine 2013, 38(23):2049-2055.

14. Beghe $C$, Wilson A, Ershler WB: Prevalence and outcomes of anemia in geriatrics: a systematic review of the literature. The American journal of medicine 2004, 116 Suppl 7A:3s-10s.

15. Nadler SB, Hidalgo JH, Bloch T: Prediction of blood volume in normal human adults. Surgery 1962, 51(2):224-232. 
16. Gross JB: Estimating allowable blood loss: corrected for dilution. Anesthesiology 1983, 58(3):277280.

17. Sehat KR, Evans RL, Newman JH: Hidden blood loss following hip and knee arthroplasty. Correct management of blood loss should take hidden loss into account. The Journal of bone and joint surgery British volume 2004, 86(4):561-565.

18. Wen L, Jin D, Xie W, Li Y, Chen W, Ding J, Xu J, Ren D: Hidden Blood Loss in Posterior Lumbar Fusion Surgery: An Analysis of Risk Factors. Clinical spine surgery 2018, 31(4):180-184.

19. Huang YH, Ou CY: Significant Blood Loss in Lumbar Fusion Surgery for Degenerative Spine. World neurosurgery 2015, 84(3):780-785.

20. Tse EY, Cheung WY, Ng KF, Luk KD: Reducing perioperative blood loss and allogeneic blood transfusion in patients undergoing major spine surgery. The Journal of bone and joint surgery American volume 2011, 93(13):1268-1277.

21. Jiang $C$, Chen TH, Chen ZX, Sun ZM, Zhang H, Wu YS: Hidden blood loss and its possible risk factors in cervical open-door laminoplasty. The Journal of international medical research 2019, 47(8):36563662 .

22. Wen L, Jin D, Xie W, Li Y, Chen W, Zhang S, Jiang X: Hidden Blood Loss in Anterior Cervical Fusion Surgery: An Analysis of Risk Factors. World neurosurgery 2018, 109:e625-e629.

23. Nuttall GA, Horlocker TT, Santrach PJ, Oliver WC, Jr., Dekutoski MB, Bryant S: Predictors of blood transfusions in spinal instrumentation and fusion surgery. Spine 2000, 25(5):596-601.

24. Meert KL, Kannan S, Mooney JF: Predictors of red cell transfusion in children and adolescents undergoing spinal fusion surgery. Spine 2002, 27(19):2137-2142.

25. Xu S, Liang Y, Wang J, Yu G, Guo C, Zhu Z, Liu H: Blood Loss of Posterior Lumbar Interbody Fusion on Lumbar Stenosis in Patients With Rheumatoid Arthritis: A Case-Control Study. Spine 2019, 44(17):E1045-e1052.

26. Owens RK, 2nd, Crawford CH, 3rd, Djurasovic M, Canan CE, Burke LO, Bratcher KR, McCarthy KJ, Carreon LY: Predictive factors for the use of autologous cell saver transfusion in lumbar spinal surgery. Spine 2013, 38(4):E217-222.

27. Yin H, He X, Luo Z, Chen J, Zhou W, Wang A: Analysis of related risk factors of hidden blood loss after anterior cervical fusion. Der Orthopade 2019, 48(7):618-625.

28. Gao F, Guo W, Sun W, Li Z, Wang W, Wang B, Cheng L, Kush N: Correlation between the coverage percentage of prosthesis and postoperative hidden blood loss in primary total knee arthroplasty. Chinese medical journal 2014, 127(12):2265-2269.

29. Yin M, Chen G, Yang J, Tong Z, Xu J, Huang Q, Ma J, Mo W: Hidden blood loss during perioperative period and the influential factors after surgery of thoracolumbar burst fracture: A retrospective case series. Medicine 2019, 98(13):e14983.

30. Erskine JG, Fraser C, Simpson R, Protheroe K, Walker ID: Blood loss with knee joint replacement. Journal of the Royal College of Surgeons of Edinburgh 1981, 26(5):295-297. 


\section{Figures}

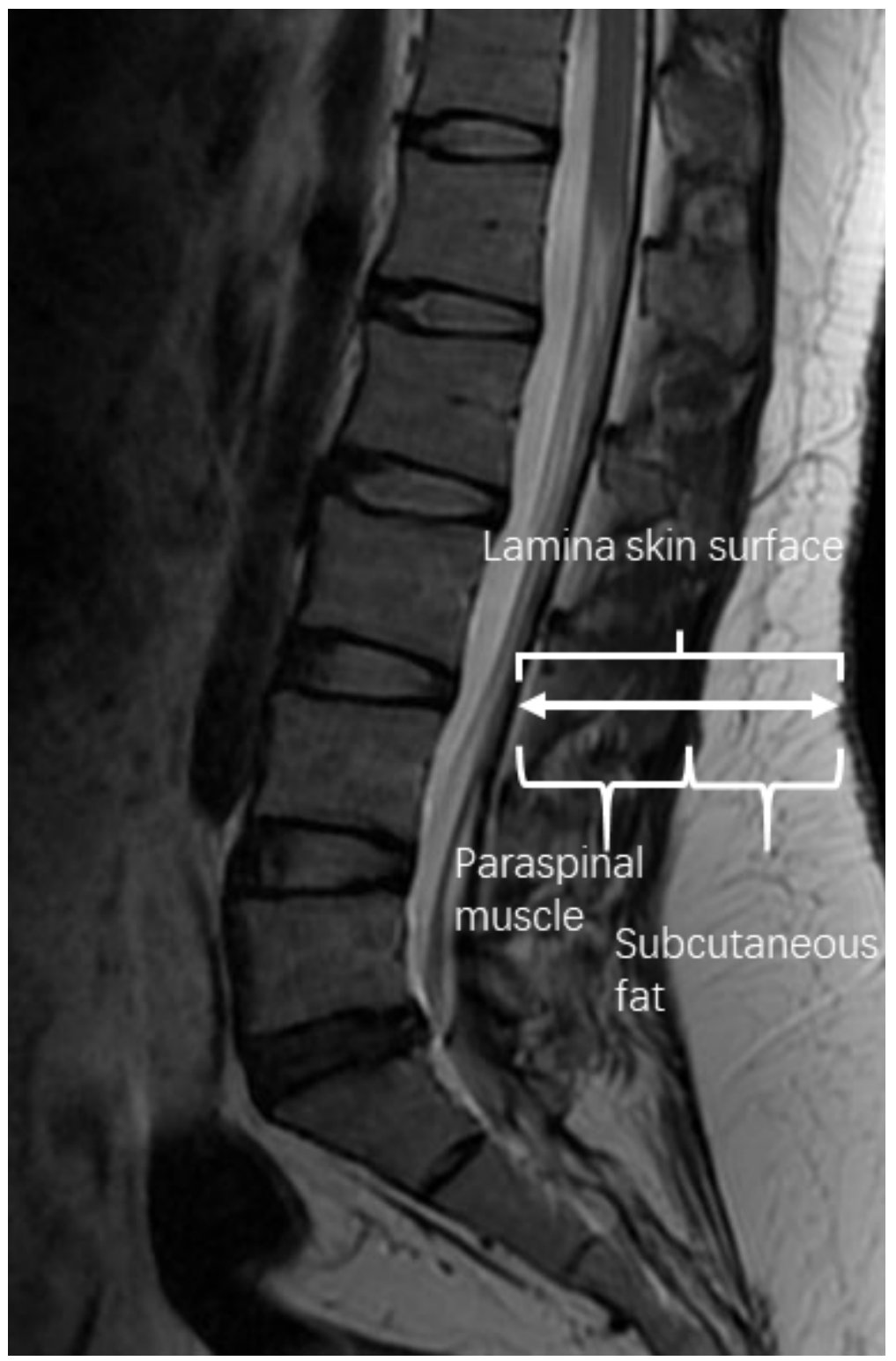

\section{Figure 1}

Diagram of the method used to measure the paraspinal muscle, subcutaneous fat, and lamina at skin surface at the level of L4 using sagittal views was determined on T2 weighted MRI. 